\title{
DOES INTRAOPERATIVE HYPEROXIA INCREASE CARDIOVASCULAR COMPLICATIONS AFTER COLORECTAL SURGERY?
}

\author{
Laura Castelltort, Marc Sadurní, Pedro Rivera, Laia Bosch, Adela Benítez-Cano, Lluís Gallart
}

Hospital del Mar, Dept of Anaesthesiology \& Intensive Care, Barcelona, Spain.

\section{BACKGROUND AND GOAL OF THE STUDY}

In 2016 the World Health Organization strongly recommended intraoperative high inspired oxygen fraction $(>80 \%)$ to reduce the incidence of surgical site infection (SSI) ${ }^{1}$.

However some authors warned about the potential increase of cardiovascular complications when applying this therapy².

The goal of the study was to audit if $80 \% \mathrm{FiO}_{2}$ administered increased cardiovascular complications when compared to standard therapy $(<50 \%$ $\mathrm{FiO}_{2}$ ).

\section{MATERIAL AND METHODS}

We reviewed the patients scheduled for elective oncologic colorectal surgery in 2015.

We divided them according to the intraoperative $\mathrm{FiO}_{2}$ received into two groups: Hyperoxia Group ( $\mathrm{HG})\left(\mathrm{FiO}_{2}>80 \%\right)$ and Control Group (CG) $\left(\mathrm{FiO}_{2}<50 \%\right)$.

We recorded demographic data (gender, age, ASA status and preoperative anaemia), previous cardiovascular disease (ischaemic heart disease, congestive heart failure and arrhythmia) and coronary risk factors (hypertension, obesity, diabetes, dyslipidemia and smoking). We also recorded intraoperative data (type and duration of surgery).

We reviewed medical charts to determine the incidence of acute coronary syndrome (myocardial infarction or angina pectoris) and other cardiovascular complications (arrhythmia, congestive heart failure or stroke) in the immediate postoperative period (up to 30 days) and in the delayed postoperative period (up to 2 years).

Statistical analysis: Fisher test to compare demographic data and also the incidence of the complications between the 2 groups. $P$ value $<0.05 \%$ was considered as significant.

\section{RESULTS AND DISCUSSION}

We included 100 patients divided between HG $(n=53)$ and $C G(n=47)$. No differences were found between groups according to demographic or intraoperative data, preoperative cardiovascular disease or coronary risk factors. Table 1.

\begin{tabular}{|c|c|c|}
\hline & HYPEROXIA GROUP $(n=53)$ & CONTROL GROUP $(n=47)$ \\
\hline Sex (male) & $58 \%$ & $55 \%$ \\
\hline Age (years) & $70 \pm 13$ & $72 \pm 12$ \\
\hline ASA I:II:III:IV & $5 \%: 63 \%: 29 \%: 3 \%$ & $4 \%: 60 \%: 30 \%: 6 \%$ \\
\hline $\begin{array}{l}\text { Previous cardiovascular } \\
\text { disease }\end{array}$ & $30 \%$ & $38 \%$ \\
\hline Ischaemic heart disease & $11 \%$ & $14 \%$ \\
\hline $\begin{array}{l}\text { Coronary Risk Factors } \\
\text { Hypertension }\end{array}$ & & $70 \%$ \\
\hline $\begin{array}{l}\text { Hypertension } \\
\text { Diabetes Mellitus }\end{array}$ & $\begin{array}{l}60 \% \\
26 \%\end{array}$ & $23 \%$ \\
\hline Dyslipidemia & $25 \%$ & $18 \%$ \\
\hline Current Smoking & $38 \%$ & $40 \%$ \\
\hline BMI $\geq 30$ & $27 \%$ & $30 \%$ \\
\hline$\geq 3$ Risck factors & $24 \%$ & $30 \%$ \\
\hline $\begin{array}{l}\text { Pre-operative haemoglobin } \\
(\mathrm{g} / \mathrm{dL})\end{array}$ & $12.7 \pm 2$ & $12.0 \pm 2$ \\
\hline Diagnosis: cancer & $93 \%$ & $98 \%$ \\
\hline Types of surgery & & \\
\hline Right hemicolectomy & $42 \%$ & $45 \%$ \\
\hline Rectal resection & $19 \%$ & $21 \%$ \\
\hline Sigma resection & $26 \%$ & $23 \%$ \\
\hline Others (colectomy...) & $13 \%$ & $11 \%$ \\
\hline Laparoscopic surgery & $72 \%$ & $65 \%$ \\
\hline Duration of surgery (min) & $250 \pm 73$ & $236 \pm 84$ \\
\hline Vasoactive drugs & & \\
\hline Ephedrine (mg) & $9 \pm 4$ & $10 \pm 6$ \\
\hline Phenilephrine (mcg) & $210 \pm 100$ & $196 \pm 120$ \\
\hline $\begin{array}{l}\text { Perioperative blood } \\
\text { transfusion }\end{array}$ & $18 \%$ & $24 \%$ \\
\hline
\end{tabular}

In the 30-days postoperative period, the incidence of acute coronary syndrome was $0 \%$ in $\mathrm{HG}$ and $4.2 \%(\mathrm{n}=2)$ in CG. Incidence of other cardiovascular complications was $2 \%$ in $H G$ and $8.5 \%$ in $\mathrm{CG}$. No significant differences were observed.

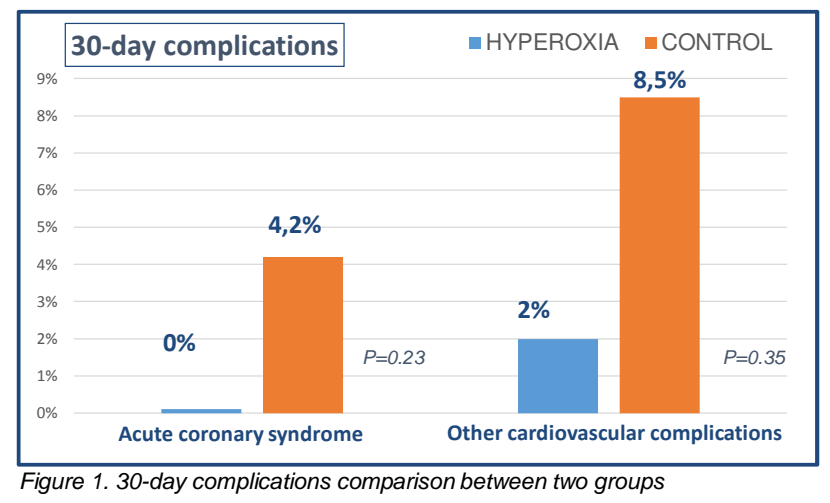

In the 2-year postoperative period, the incidence of acute coronary syndrome was $3.7 \%$ in $\mathrm{HG}$ and $2 \%$ in CG. The incidence of other cardiovascular complications was $17 \%$ vs $13 \%$ respectively. No significant differences were observed between two groups.

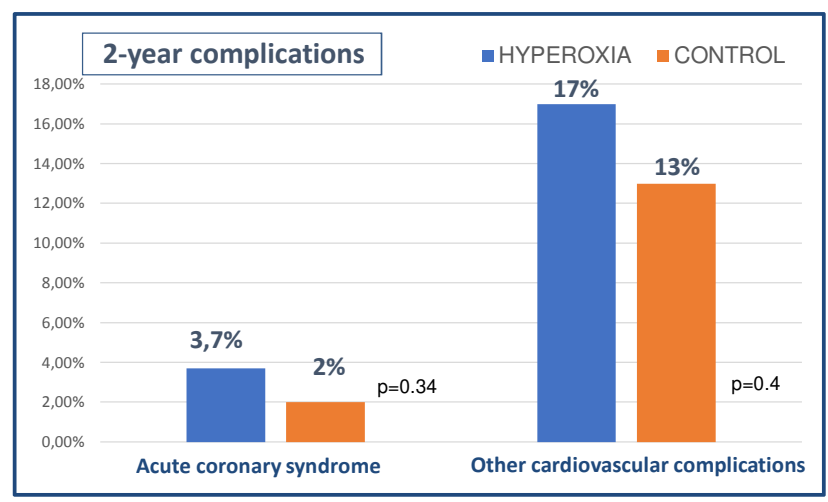

Figure 2. 2-year complications comparison between two groups

\section{CONCLUSIONS}

Immediate or delayed cardiovascular complications doesn't seems to increase when applying hyperoxia to patients scheduled to elective colorectal surgery.

\section{REREFERENCES}

1.Global Guidelines for the Prevention of Surgical Site Infection. Geneva: World Health Organization; 2016.

2.Fonnes $\mathrm{S}$ et al. Perioperative hyperoxia - Long-term impact on cardiovascular complications after abdominal surgery, a post hoc analysis of the PROXI trial. Int J Cardiol. 2016 Jul 15;215: 238-43. 